\title{
A Case Study on Scientific Attempt to Turn Agriculture Scetor Sustainable, Profitable and Attractive Through Innovative Aquaphonic Farming Methods in Cuttack and Khordha Districts of Odisha, India
}

\author{
Usharani Sahu \\ Department of Economics, Mittal School of Business \\ Lovely Professional University, Jalandhar
}

\begin{abstract}
Decreasing availability of land for farming due to Urbanization and Industrialization has further complicated Wide spread difference between cost of Agricultural Production-Minimum Support Price (MSP). To resolve the issues of viability in terms of economic \& financial return and to find out alternative methods have to be applied in farming sector.Use of innovative technology, the less numners of persons have been employed which obtained better results,less area under innovative farming has resulted in higher yield..As per suitability non-traditional methods to be implemented at large scale by the assistance of Government mechanism for the betterment of society. Agriculture has to be climate smart, technology driven, profit generating and sustainable to meet the need of food security of the country
\end{abstract}

Keywords:- Sustainable Development, Food Security, Innovative farming, Aquaphonic farming, Nutritional supplement, Employment generation, market driven economy.

\section{INTRODUCTION}

The agricultural sector has turned less atractive for rural mass, less profitable profession for the rural youth and less incentive generator for the micro level enterprenours as well as self employed person in rural India.Despite being less attractive for us,agriculture forms the most important part of primary sector of our econony.To feed the vast population of our country we desperately need surplus agricultural production,maintain buffer stock of food grain and ensure that public distribution system works efficiently to make food grains reach to the needy in time. We have to finish hunger from the world, at the same time there are end less challenges before us like scarcity of farming land,increasing population,trend of industrialization,shift in the pattern of employment etc which come in the way of our attempt to finish the hunger from the world.Here comes the answer to meet the challenges faced by us,in the form of adoption of new technology. We need to reduce poverty, meet scarcity of food with limited land resources in the present era of vast urbanisation \& industrialisation.In order to finish the hunger from the world ,to meet the nutritional need of every human being irrespective of region and economic standard.we need to encourage Climate-smart agriculture to tackle the loss due to natural disasters.Aquaphonic farming is one of the most reliable technological method which can answer all our need in one go.Growing demand for food crop due increased Population has caused alarming situation around the globe.

Traditional farming method have to be substituted by innovative scientific processes which can ensure higher return with lower investment amount duly supported by appropriate scientific approach under controlled farming condition.Aquaphonic culture is the most suitable one to address all these subject under our consideration. Besides it is cost effective coupled with latest technology to achieve the dual purpose of food security as well as nutritional enrichment. The farmers adopting aquaphonic culture yield very high rate of profit as compared to any other methods of farming feasible in the locality.

For successful implementation of the aquaphonic farming and proper analysis of cost involved as well as benefit yield from this method of farming initially microlevel planning has to be run on pilot project basis; consequently macro-level planning has to be implemented on alarge scale basis according to the local climatic consideration. Analysis as per our study has to take all varying factors in to consideration during calculation.

\section{RESEARCH OBJECTIVES}

To device new innovative technologies to bridge the gap between the needs of the farmers and the available return on their farm production,to make feasibility studies of innovative technologies implemented around the globe: in Indian context with special attention to the ground reality in the study area.

$>$ To suggest the technology know-how, assured return on their new approaches applied in the local context ,to prepare a brief report of these innovations to be applied and implemented in the ground at micro level. 
To suggest non-traditional methods to be implemented at large scale by the assistance of Government mechanism for the betterment of society. To make optimized use of available resources with trained existing man power and use of innovative methods. To reduce poverty, meet scarcity of food with limited land resources in the era of vast urbanisation \& industrialisation in order to finish the hunger from the world in one hand at same time to meet the nutritional need of every human being irrespective of region and economic standard.

We need to encourage Climate-smart agriculture to tackle the loss due to natural disasters while promoting Women empowerment as well as ensuring one hundred percent Youth employment.

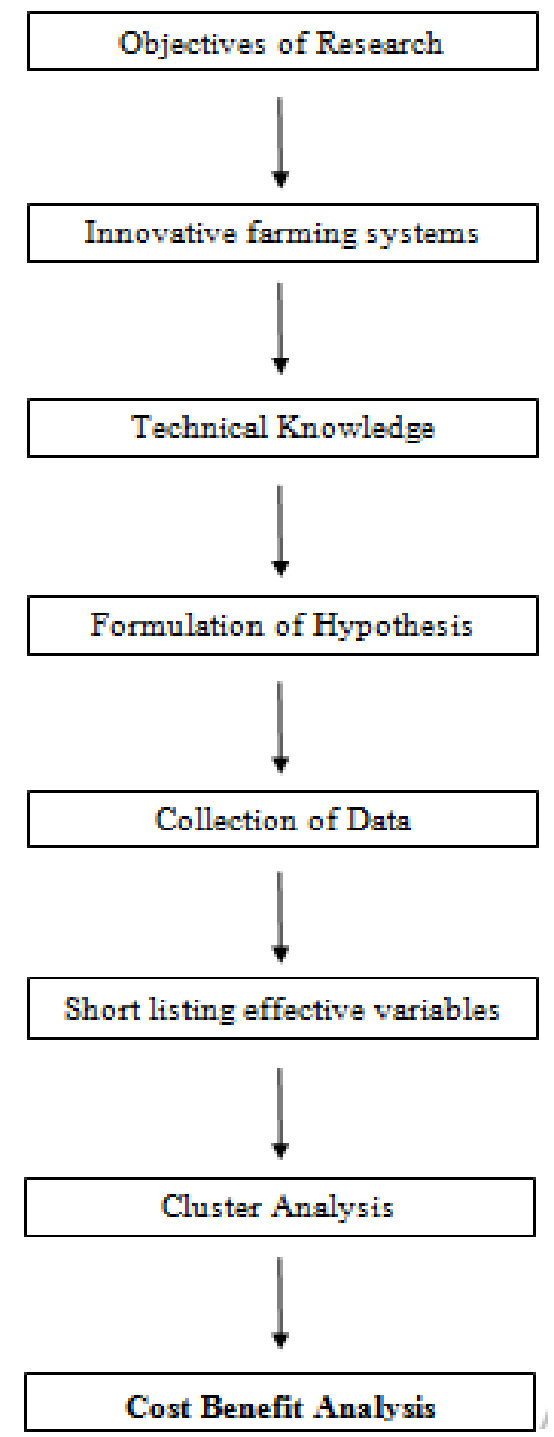

Fig 1

\section{RESEARCH METHODOLOGY}

Collection of Data:- Data have been collected with quantitative input in selected study area by survey Questionnaire method.At the sametime collection of Data from authentic sources has formed a significant supplementation to the Data collected through Questionnaire method.It has covered the study area of Cuttack and Khordha districts of Odisha.

Analysis of Data:- In scientific approach with qualitative input in varying dimensions and varying situations prevalent in the study area Collected Data are analysed. Quantitative results are taken into consideration.
Comparison of available Data: Traditional farming yield in the locality compared with collected Data on experimental aqua farming yield with due consideration to the cost involved, man power engaged and infrastructure utilized for both purposes.

Micro economic modelling, input output model

$>$ Statistical Analysis, multivariate analysis, factor analysis and cluster analysis

- Econometric Analysis, auto correlation method and time series analysis

$>$ Cost Benefit Analysis : Analysis on input cost factors and output benefit pattern has helped in forming a general opinion on feasibility study in the area. 
ISSN No:-2456-2165

Trend Analysis : To prepare collection of data through cluster sampling method. To analyze and compare the data between newly experimented areas and previously succeeded areas to find the trend.
After collection of data, analysis under different methods were done,the inference has been drawn to suggest a most viable and sustainable model with respect to the study area.

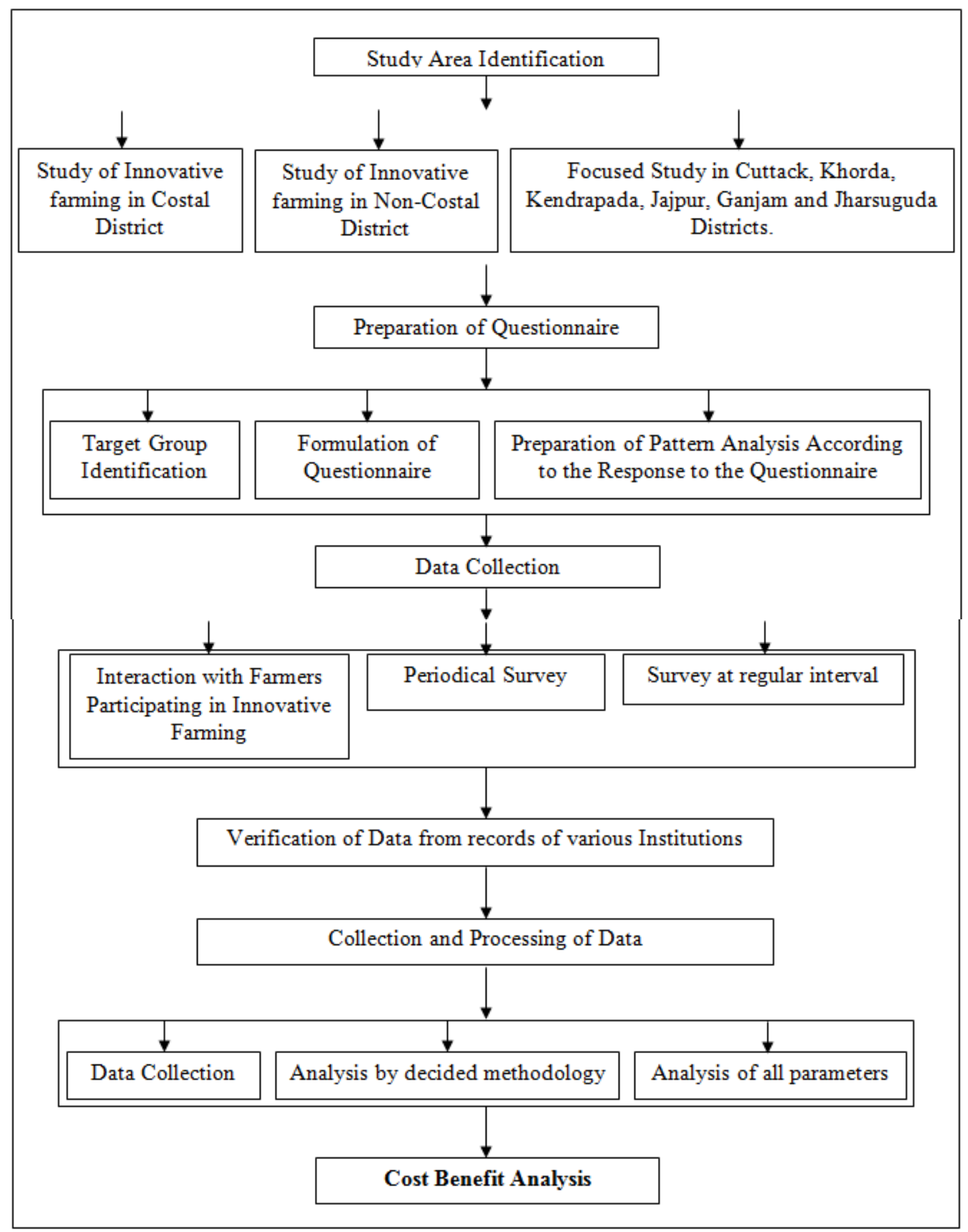

Fig 2 
In order to complete the study specialized observation made in comparison of data available at

$>$ Water And Land Management Institute (WALMI), Odisha, (ii) Odisha University of Technology (OUAT)Bhubaneswar and its extension centres at 10 different districts of the state, (iii) Central Soil Testing laboratory at Cuttack has been used for obtaining experimental innovative trails with results in different methods as required for the relevant comparison with the data collected through different procedure as described above.

Field data collection has been carried out in two phases from the month of October 2019 to March 2020 and from May 2020 to July 2020 on innovative farming in various district of Odisha with special focus in Cuttack and Khorda District of Odisha. Collection of data from various institutions has been carried out prior to collection of field data.

\section{RESULTS AND OBSERVATION}

It is observed that Input cost is very low as compared to traditional pattern of farming. The risk factors like crop failure and low yield probability have remained very low.

$>$ Output benefit pattern is quite higher than conventional farming methods. The yield is more,Climatic risk factors have no effect on this method.

$>$ Due to use of technology, the less numners of persons have been employed which obtained better results,less area under innovative farming has resulted in higher yield.A general inference on feasibility study in the area has been reached.It is suggested to utilize this farming method in a larger scale.

$>$ The method is technologically efficient,economically viable,risk is considerably lowered,needs less man power and can be utilized to generate employment in massive scale.

$>$ The crop yield in this method is resistant to climatic variation and variation in rain fall over the years. This can be extended in to the flood prone and drought prone areas of the country.

$>$ This method is proved as effective in soil conservation in the area and water consumption is very low as compared to traditional farming process.

$>$ To ensure food security and supply of nutrition in the remote areas, this method can bring about the change to the desired level.

\section{CONCLUSION}

The budget spent on developement and maintainance of irrigation facility is very high, a small part of the same when diverted towards preparation of infrastructure for innovative aquaphonic farming and towards incentive to farmers for promoting this method can bring higher crop yield, lowering the risk of crop failure. The rate of employment generation will be considerably high without any expenditure incurred on the state exchequor as the market will take care of it in the form of demand-supply chain,storage-transportation process,profit generated at different stages of production and marketing. When we compare the allocation of budget for irrigation and employment,we arrive at the conclusion that both these can be reduced by this small change in the farming method along with adaption of new technology which is resistant to variation of climatic condition and rain fall. Food security and Nutrition value addition obtained in this method will be added advantage for our society which will further reduce the pressure for allocation of budget in these areas of our state planning.A part of revenue thus remaining with Government departments due reduced need of allocation in these areas can be utilized for meeting the other needs of our state.Agricultural research and training institutions will focus more on popularizing innovative aqua farming after getting a clear research finding in this new area under scientific consideration. My research will enable them in framing their policy for training farmers in this new methods and focus on these for further better results.

\section{REFERENCES}

[1]. World Economic and Financial Surveys. Regional Economic Outlook: Sub-Saharan Africa. Recovery and New Risks, 2011.

[2]. Louwi, A., Chikazungaii, D., Haankukuiii, C. and \& Ndangaiv, L., 2009. Dynamics of the Restructuring Fresh Produce Food Markets in the Southern African Region. Paper prepared the International Association of Agricultural Economists Conference, Beijing, China, 16-22/08/2009.

[3]. Martin Webber, C. and Labaste, P., 2010.Building Competitiveness in Africa's Agriculture. A Guide to Value Chain Concepts and Applications. The International Bank for Reconstruction and Development/World Bank, 2010.UNIDO (United Nations Industrial Development Organisation), 2011 Agribusiness for Africa's Prosperity.

[4]. Eds, Yumkella, K.K., Kormawa, P.M., Roepstorff, T.M. and Hawkins, A.M. ID/440. UNIDO, 2011. USAID, 2010. Aquaculture Buyer's Guide for Nigeria. Compiled by Miller, J. W. And Aleem, S. USAID Markets Projects (Maximising Agricultural Revenue and Key Enterprisesin Targeted Sites), Oct. 2010.

[5]. Bhalerao, R.A., Charge, K.V. and Patil, V.G. 2010. Profile of the farmers practising the livestock based farming system: In $22^{\text {nd }}$ national seminar on "Role of Extension in Integrated Farming Systems for sustainable rural livelihood, $9^{\text {th }}-10^{\text {th }}$ Dec, Maharastra, pp. 29.

[6]. Chawla, N.K., Kurup, M.P.G. and Sharma, V.P. 2004. Animal Husbandry. State of Indian farmer. Amillennium study, Department of Agriculture and Cooperation, Ministry of Agriculture, Government of India, New Delhi and Academic Foundation. New Delhi.

[7]. Jagadeeshwara, K., Nagaraju, Y., Bhagyavathi and Nagaraju, K. 2011. Livelihood improvement ofvulnerable farmers through Integrated Farming Systems of Southern Karnataka. pp: 145 -146. 
[8]. Kadam, S.S., Hatey, A.A., Nikam, T.R., Landge, S.P., and Palampalley, H.Y. 2010. Constraints of IFSin Kankan region of Maharashtra - A case study. In: $22^{\text {nd }}$ national seminar on "Role of Extension in Integrated Farming Systems for sustainable rural livelihood, $9^{\text {th }}-10^{\text {th }}$ Dec, Maharastra, pp. 101.

[9]. Mahadik, R.P., Bhairamkar, M.S. and Desai, A.N. 2010. Profile of the farmers practicising the back yard poultry farming system. In: $22^{\text {nd }}$ national seminar on "Role of Extension in Integrated Farming Systems for sustainable rural livelihood, 9th $-10^{\text {th }}$ Dec, Maharastra, pp. 30-31.

[10]. Manivannan, A., Mathialagan, P. and Narmatha, N. 2011. Goat based farming system in Tamilnadu,pp. 163.

[11]. Mohanty, D., Patnaik, S.C., Jeevan Das, P., Parida, N.K. and Nedunchezhiyan, M. 2010. Sustainable livelihood: a success story of a tribal farmer. Orissa Review, September: 41 - 43.

[12]. Nageswaran, M., Selvaganapathy, E., Subbiah, V.R. and Nair, S. 2009. Demonstration and Replication of Integrated Farming Systems at Chidambaram. Report of M.S. Swaminathan Research Foundation(MSSRF), Chennai, pp. $16-53$. 